\title{
Redes sociais, capital social e governança ambiental no Território Portal da Amazônia
}

\author{
Frédéric MERTENS ${ }^{1}$, Renata TÁVORA², Igor Ferraz da FONSECA ${ }^{3}$, Raquel GRANDO ${ }^{4}$, Mauro CASTRO5, \\ Kátia DEMEDA ${ }^{6}$
}

\section{RESUMO}

O artigo trata de um estudo empírico em que a análise de redes sociais é utilizada para mapear o capital social de atores envolvidos em processos de governança ambiental na Amazônia brasileira. Por meio de entrevistas, foi mapeada a rede de relaçóes de diálogo sobre questóes socioambientais de um conjunto de 505 atores no Território Portal da Amazônia. Foram identificadas 3384 relaçôes de diálogo, com uma média de 6,7 parceiros de diálogo por ator. A análise dos aspectos estruturais da rede de diálogo foi utilizada para construir indicadores de capital social de ligação, com mapeamento da organização interna dos atores de um mesmo município, e de conexão, com a caracterização das relaçóes entre atores de municípios diferentes. Em nível municipal, a distribuiçấo das duas formas de capital social permitiu caracterizar os grupos de atores de acordo com as suas atuações diferenciadas na governança ambiental do Território. Em nível territorial, o padrão de conectividade entre os 16 municípios mostra um equilíbrio entre as duas formas de capital social e revela o potencial de comunicaçáo e organizaçáo dos atores, como demonstrado no exemplo dos projetos de Agendas 21 locais. Estes resultados demonstram como a análise de redes sociais pode contribuir na definição (ou redefinição) das fronteiras dos territórios de modo a incluir um conjunto de municípios cujos atores mantêm relaçôes sociais efetivas. Açóes de governança no Portal da Amazônia são propostas com potencial para fortalecer os processos de diálogo, diminuir os conflitos e promover o uso sustentável dos recursos naturais na Amazônia.

PALAVRAS-CHAVE: Governança ambiental, redes sociais, capital social, Portal da Amazônia, gestão dos recursos naturais.

\section{Social networks, social capital and environmental governance in the Amazonian Gateway Territory}

\begin{abstract}
The article presents an empirical study where social network analysis is used to map social capital among actors involved in environmental governance processes in the Brazilian Amazon. Using interviews, we carried out the mapping of the dialogue network regarding socio-environmental issues among 505 actors from the Amazonian Gateway Territory. The analysis identified 3384 dialogue relationships. Each actor has an average of 6,7 dialogue partners. The analysis of the structural characteristics of the dialogue network was used to build indicators of social capital of the bonding type, based on the mapping of the organization among actors from the same municipalities, and bridging type, based on the identification of relationships among actors from different municipalities. At the municipal level, the distribution of the two types of social capital allowed the characterization of groups of actors according to their differing participation in the environmental governance of the Territory. At the territorial level, the connectivity pattern among the 16 municipalities exhibits a balance between the two types of social capital and reveals the potential of communication and organization among actors, as demonstrated through the example of the local Agenda 21 projects. These results demonstrate how social network analysis can contribute to the definition (or re-definition) of the territories frontiers in order to include a set of municipalities whose cohesion is based on effective social relationships. We also propose governance actions for the Amazonian Gateway aiming at strengthening dialogue processes, reducing conflicts and promoting the sustainable use of natural resources in the Amazon.
\end{abstract}

KEYWORDS: Environmental governance, social networks, social capital, territory development, natural resources management.

\footnotetext{
1 Centro de Desenvolvimento Sustentável - Universidade de Brasília

Campus Universitário Darcy Ribeiro - Gleba A, Bloco C - Av. L3 Norte, Asa Norte - Brasília-DF, CEP: 70.904-970 E-mail: fmertens@unb.br

${ }^{2}$ Comunidade de Prática sobre a Abordagem Ecossistêmica em Saúde Humana na América Latina e no Caribe (CoPEH-LAC), Centro de Desenvolvimento Sustentável, Universidade de Brasília. E-mail: renata.tavora@gmail.com

${ }^{3}$ Centro de Desenvolvimento Sustentável - Universidade de Brasília. Instituto de Pesquisa Econômica Aplicada - IPEA. E-mail: Igor.fonseca@ipea.gov.br

${ }^{4}$ Centro de Desenvolvimento Sustentável, Universidade de Brasília. Email: raquelscg@yahoo.com

${ }^{5}$ Núcleo de Altos Estudos Amazônicos - Universidade Federal do Pará. E-mail: mauroandrec@yahoo.com.br

${ }^{6}$ Instituto de Filosofia e Ciências Humanas - Programa de Pós-Graduação em Ciências Sociais - Universidade Federal do Pará. Email: katiademeda@ufpa.br
} 


\section{INTRODUÇÃO}

Governança ambiental se refere a processos e interaçóes entre atores sociais e institucionais na gestáo dos recursos naturais e no desenvolvimento sustentável. Os processos de governança ambiental apresentam dificuldades intrínsecas associadas às dinâmicas socioambientais complexas, às interaçóes entre níveis e entre escalas, a fenômenos de emergências e à existência de mudanças abruptas vinculadas a limiares (Folke et al. 2005; Cash et al. 2006; Lemos e Agrawal 2006). Para Grindle (2004) governança possui diversos componentes que incluem: poder, legitimidade e autoridade entre instituiçôes; regras e normas que determinam a tomada de decisão; relaçóes de responsabilização entre os atores; habilidade do governo em fazer políticas e prover bens e serviços; e influência das instituiçôes e políticas sobre o bem-estar público. Os processos de governança ambiental levam os diferentes atores, entre eles, gestores governamentais, membros da sociedade civil, pesquisadores e empresários, a interagirem para definir açóes a serem implementadas por meio de estratégias de gestão ambiental (Lemos e Agrawal 2006). Estes atores, com valores, prioridades e interesses diversificados e frequentemente conflitantes, respondem a numerosos desafios que incluem trocas de informação e construção de conhecimentos compartilhados, além de articulação intersetorial para conciliar as prioridades econômicas, sociais e ambientais (Dietz et al. 2003; Pretty 2003; Newman e Dale 2007).

Diversos autores sugerem que as redes sociais e o capital social fortalecem os processos de governança e favorecem o uso sustentável dos recursos naturais (Woolcock e Narayan 2000; Pretty 2003; Grafton 2005; Bodin et al. 2006; Carlsson e Sandström 2008; Bodin e Crona 2009). A articulação em rede entre os atores se apresenta como estratégia para gestão de conflitos, possibilitando uma atuação mais coordenada que atenda aos diferentes interesses (Carlsson e Sandström 2008; Bodin e Crona 2009). O capital social dos atores pode favorecer os processos de governança ambiental, pois promove relaçóes de confiança, reciprocidade na troca de informação e recursos, criação de normas, diminuição dos custos de fiscalização e construção de uma visão de futuro compartilhada (Pretty e Ward 2001; Dietz et al. 2003).

Apesar de notáveis exceçóes (Schneider et al. 2003; Crona e Bodin 2006; Bodin e Crona 2008; Sandström 2008), existe uma carência de estudos empíricos baseados no mapeamento dos aspectos estruturais das redes sociais e na utilização de indicadores de capital social para analisar os processos de governança ambiental. $\mathrm{O}$ presente artigo apresenta um estudo em que é mapeada a rede de relaçóes de diálogo entre um conjunto de atores envolvidos na gestão dos recursos naturais de um território da Amazônia brasileira, no intuito de analisar as relaçóes entre o capital social e os processos de governança ambiental.

\section{Redes sociais e governança ambiental}

Diversos estudos apontam para um papel importante das redes sociais nos processos de governança ambiental. As redes sociais foram identificadas como formas de organização que possuem potencial de conectar os atores que pertencem a diversas categorias e níveis, de modo a criar estruturas flexíveis e adaptativas de governança (Bodin e Crona 2009; Scherer-Warren 2006). Estas estruturas, que envolvem atores de categorias diversas, tais como pesquisadores, gestores governamentais, organizaçóes não governamentais e movimentos sociais, também contribuem para facilitar a formulação de soluçóes adaptadas à complexidade dos problemas socioambientais por meio de processos transdisciplinares (Forget e Lebel 2001). Além disso, a flexibilidade das redes pode favorecer a adaptação à constante evolução das problemáticas socioambientais (Carlsson e Sandström 2008; Mertens et al. 2008). Existem também evidências que os processos de gestão fomentados por meio de redes sociais podem ser mais efetivos que os instrumentos de comando e controle operados pelas instituiçóes formais (Holling e Meffe 1996; Pretty 2003). Diversos autores enfatizam o papel das conexóes entre atores e instituiçóes que atuam em diversos níveis - local, regional, nacional e global e defendem que formas de governança ambiental multinível são chaves para responder melhor aos desafios da gestão dos sistemas socioambientais, em que processos ecológicos, sociais e econômicos estabelecem inter-relaçóes entre escalas espaciais e temporais (Cash et al. 2006; Brondizio e Ostrom 2009). Além disso, redes sociais densas que interligam atores que pertencem a diversos setores da sociedade podem favorecer a distribuição equitativa das oportunidades de desenvolvimento entre atores e instituiçóes (Abramovay 2000; Mertens et al. 2005).

Estudos empíricos que analisam as propriedades estruturais e funcionais das redes de atores baseiam-se nos conceitos teóricos e metodológicos da análise das redes sociais (Marin e Wellman 2010; Scott 2000). Esta abordagem permite estudar os padróes de organização dos atores sociais e analisar quais aspectos estruturais das redes sáo mais eficientes para prover formas de governança adaptadas à complexidade dos sistemas socioambientais (Schneider et al. 2003; Crona e Bodin 2006; Sandström 2008). Diversos estudos que utilizam as redes sociais para analisar os processos de governança ambiental introduzem o conceito de capital social, que tem sido associado à capacidade de organização dos grupos sociais (Pretty e Ward 2001). Além disso, a aproximação entre os conceitos de organização em rede e capital social é particularmente oportuna em estudos empíricos porque medidas de redes sociais podem ser utilizadas para quantificar o capital social 
dos grupos de atores (Borgatti et al. 1998; Bodin e Crona 2008). A seguir, apresentamos as relaçóes entre os conceitos de redes sociais e de capital social, com ênfase em aplicaçôes no campo da governança ambiental.

\section{Redes sociais e capital social}

Uma rede é formada por um conjunto de elementos chamados de nós, com conexóes entre eles, chamadas de elos. Uma rede social é um conjunto de indivíduos conectados entre si por meio de relaçôes sociais específicas (Wasserman e Faust 1994). A análise de redes sociais estuda os padróes de interaçôes entre os indivíduos e foi amplamente utilizada em diversas áreas do conhecimento para explicar fenômenos relacionados, por exemplo, à saúde, ao trabalho, à organizaçáo comunitária e à difusão das inovaçóes (Marin e Wellman 2010). As redes sociais são analisadas por meio da integração de dados atributivos (as características dos indivíduos) e relacionais (os elos entre os indivíduos). Os dados relacionais são chave na análise de redes sociais, pois sấo utilizados para revelar o padrão de interação entre os indivíduos.

O capital social é um conceito multidimensional (ver Portes 1998 para uma revisão) que encontrou nos campos do desenvolvimento sustentável, da gestáo dos recursos naturais e da governança ambiental um fértil campo de aplicaçáo (Pretty 2003; Bouma et al. 2008; Brondizio e Ostrom 2009). A ideia de que as redes sociais estão intimamente ligadas ao conceito de capital social é encontrada nas suas diversas acepçóes, seja ele definido como recursos associados a redes de relaçôes mútuas (Bourdieu 1980), como a estrutura das relaçóes entre atores que promovem atividades produtivas (Coleman 1988), ou como as características da organização social, incluindo a confiança, as normas e a reciprocidade, que facilitam açôes coletivas (Putnam 1995). Os recursos disponíveis e mobilizados por meio das relaçóes sociais variam de acordo com a estrutura da rede, com potencial para favorecer ou, ao contrário, agir como uma barreira para o desenvolvimento da confiança, a reciprocidade de trocas e a ação coletiva (Pretty e Ward 2001; Bebbington, 2004; Bodin e Crona 2009).

O capital social pode ser definido em nível individual ou do grupo (Borgatti et al. 1998). Em nível individual, o capital social está associado ao acesso e à utilização dos recursos que permeiam as redes sociais (Lin 1999), bem como ao poder social do indivíduo, que se utiliza de seus contatos e dos recursos mobilizados pela rede para promover seus interesses (Bourdieu 1980). Em nível do grupo, o capital social pode ser visto como um recurso coletivo com potencial para aumentar a qualidade de vida das comunidades, para promover a ação coletiva e o fortalecimento da colaboração (Coleman 1988; Putnam 1995; Lin 1999; Pretty 2003).

Os grupos podem ser caracterizados por dois tipos distintos de capital social: de ligação (bonding) e de conexão (bridging)
(Woolcock e Narayan 2000). As relaçóes entre atores que pertencem a um mesmo grupo social estão associadas ao capital social de ligação (Putnam 1995). Este tipo de capital social, associado à existência de relaçóes de confiança, reciprocidade e coesão do grupo, favorece as trocas de informação e, potencialmente, o desenho de estratégias compartilhadas, o consenso sobre normas reguladoras, a promoção da açáo coletiva e a gestấo dos conflitos internos ao grupo (Bebbington e Perreault 1999; Woolcock e Narayan 2000). As relaçôes entre atores que pertencem a grupos sociais distintos estão associadas ao capital social de conexão (Granovetter 1973). As fronteiras entre os grupos podem ser de natureza geográfica, étnica, social, política, cultural, ou associadas a interesses específicos que podem variar ao longo do tempo. O capital social de conexão favorece o acesso a ideias novas, ao diálogo entre pontos de vista diversos e à mobilização de recursos que não estáo disponíveis dentro do seu próprio grupo (Granovetter 1973; Woolcock e Narayan 2000).

Os dois tipos de capital social podem fortalecer os processos de governança ambiental. O capital social de ligaçáo pode reduzir os conflitos, fomentar a confiança, diminuir os custos de fiscalização e consolidar o grupo internamente para a gestão coletiva dos recursos naturais comuns (Pretty e Ward 2001). O capital social de conexấo oferece a oportunidade de responder às limitaçôes tanto da gestão de cima para baixo, que não se embasa na realidade local (Holling e Meffe 1996), quanto da gestáo totalmente descentralizada, que não leva em consideração os impactos locais dos fenômenos sociais e ambientais regionais ou globais (Cash et al. 2006; Armitage 2008). Conexôes entre grupos sociais distintos e em diversos níveis também têm potencial de promover as trocas de informação e a colaboração entre atores com experiências diversificadas de modo a assegurar flexibilidade e capacidade de adaptação (Newman e Dale 2007). Alguns autores defendem que um equilíbrio entre as duas formas de capital social é importante para os processos de governança ambiental (Bodin e Crona 2009; Brondizio e Ostrom 2009).

O conjunto de estudos apresentados acima aponta para a análise de redes sociais como uma oportuna abordagem, tanto teórica quanto metodológica, para estudar o capital social de grupos de atores envolvidos em processos de governança ambiental. Assim, no presente estudo, utilizamos esta abordagem para mapear e mensurar o capital social de grupos de atores envolvidos na governança ambiental do Território Portal da Amazônia, localizado na Amazônia brasileira.

\section{O Território Portal da Amazônia}

Um território pode ser definido como um espaço físico, geograficamente delimitado, cujas fronteiras são estabelecidas por critérios multidimensionais, tais como meio ambiente, economia, etnia, sociedade, cultura e instituiçōes (SDT/ MDA 2005). Segundo Abramovay (2000), o nível territorial 
oferece um espaço social adequado para a emergência de ideias inovadoras que podem subsidiar açôes para o desenvolvimento sustentável. O Portal da Amazônia integra um dos Territórios da Cidadania - programa do governo federal do Brasil que incentiva açóes nas áreas de produção, promoção da cidadania, do desenvolvimento social e de infra-estrutura (SDT/MDA 2005). O Portal da Amazônia está localizado na Amazônia brasileira, no extremo norte do estado do Mato Grosso, é formado por 16 municípios que ocupam uma área de 108.000 $\mathrm{km}^{2}$ e integra duas importantes bacias hidrográficas do rio Amazonas: a bacia do rio Tapajós e a bacia do rio Xingu (Figura 1) (Fundação Cândido Rondon 2005; SDT/MDA 2005). Este Território se encontra em área de fronteira agrícola e de extensa produçáo agropecuária, nos limites iniciais da floresta amazônica, conhecida como "arco do desmatamento". Forma uma zona tampão, com forte pressão antrópica, associada às atividades de pecuária e exploraçâo madeireira, localizada entre extensas áreas de monocultura da soja ao sul e um conjunto de áreas protegidas localizadas ao norte (Ministério do Desenvolvimento Agrário 2006). Esta regiāo é considerada de extrema importância para a preservação, conservação e uso sustentável da biodiversidade e recursos naturais.

O Território Portal da Amazônia foi criado com o propósito de unir municípios com aspectos econômicos, ambientais, sociais e culturais compartilhados em torno de um objetivo de desenvolvimento (Fundação Cândido Rondon 2005). Porém, até hoje, a região é caracterizada

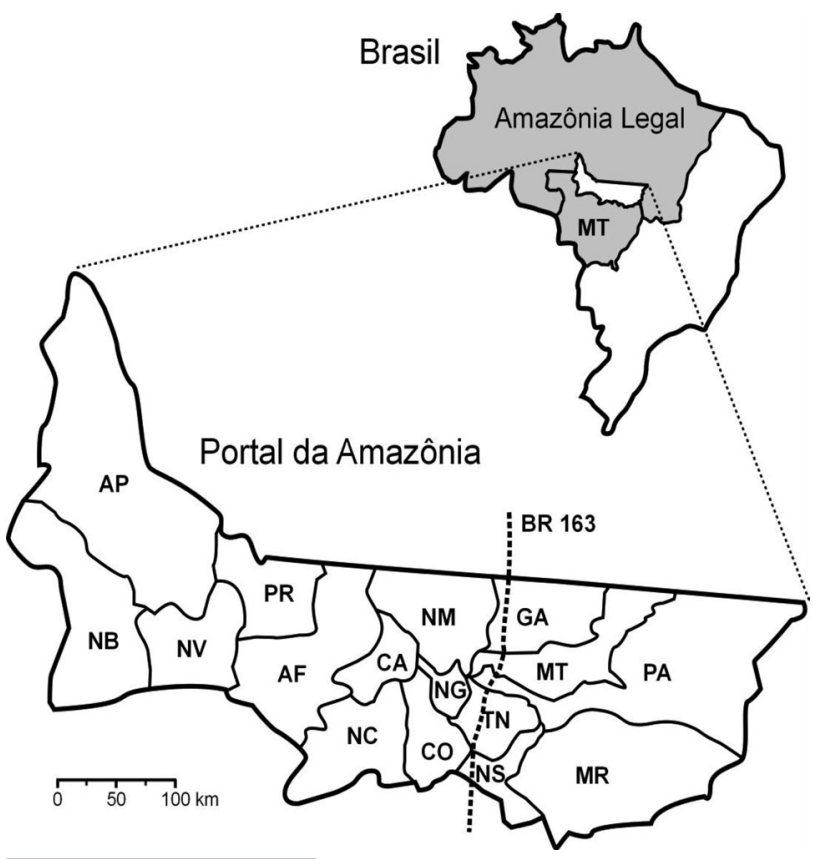

Figura 1 - Mapa do Portal da Amazônia. 0 Portal da Amazônia encontra-se no Estado de Mato Grosso (MT), na região da Amazônia Legal, no Brasil. Ver material e métodos para a legenda dos nomes dos municípios. por múltiplos problemas socioambientais, que incluem desmatamento, desordenamento territorial, invasão e venda de terras públicas, abertura de estradas vicinais para atividades madeireiras e expulsão de pequenos agricultores (de Oliveira 2009). A persistência de conflitos relacionados à posse de terras e ao acesso e uso dos recursos naturais levanta a questáo da capacidade de governança dos atores do Território. De Oliveira (2009) destaca, porém, a recente abertura de novos espaços públicos de participaçáo, onde os movimentos sociais têm a oportunidade de dialogar com os diversos níveis de governo em torno do planejamento socioambiental da área de influência da BR-163 onde o Território está inserido.

Neste contexto de conflitos e oportunidades para os processos de governança ambiental no Portal da Amazônia, é importante analisar as formas de interaçóes entre atores sociais do Território. No intuito de contribuir para esta análise, o presente estudo tem os seguintes objetivos: 1 . identificar e caracterizar um conjunto de atores relevantes em relação às questôes socioambientais no Território; 2 . mapear a rede de diálogo sobre as questôes socioambientais entre estes atores; 3. analisar e comparar os padróes das relaçóes de diálogo entre os atores em cada município do Território por meio de indicadores de capital social de ligação e de conexão e 4. analisar as possíveis relaçôes entre o diálogo no Território e os processos de governança ambiental, utilizando o exemplo da implantação das Agendas 21 locais.

\section{MATERIAL E MÉTODOS}

\section{População de estudo e construção da rede de diálogo}

As entrevistas foram realizadas entre julho e dezembro de 2006 nos 16 municípios do Portal da Amazônia: Alta Floresta (AF), Apiacás (AP), Carlinda (CA), Colíder (CO), Guarantã do Norte (GA), Marcelândia (MR), Matupá (MT), Nova Bandeirantes (NB), Nova Canaã do Norte (NC), Nova Guarita (NG), Nova Monte Verde (NV), Nova Santa Helena (NS), Novo Mundo (NM), Paranaíta (PR), Peixoto de Azevedo (PA), Terra Nova (TN). O critério para a escolha dos indivíduos a serem entrevistados seguiu a metodologia da "bola de neve" (Scott 2000), que consiste em entrevistar um número inicial de atores para identificar novos atores a serem entrevistados e assim por diante. $\mathrm{O}$ grupo inicial de atores a serem entrevistados foi escolhido a partir da lista dos membros do Conselho Executivo das Açóes da Agricultura Familiar (CEAAF), que reúne 60 instituiçóes tais como: Conselhos Municipais de Desenvolvimento Rural Sustentável, prefeituras municipais, membros dos movimentos sociais, ONGs locais, sindicatos rurais patronais, sindicatos de trabalhadores rurais, órgãos públicos, entre outros. Esta lista foi escolhida porque os membros do CEAAF têm um papel relevante nas questôes 
socioambientais, representam diversas categorias de atores, e estão presentes em todos os municípios do Portal da Amazônia. Foram entrevistados 53 membros dos CEAAF, distribuídos entre os 16 municípios do Portal da Amazônia, para iniciar o processo de bola de neve.

$\mathrm{Na}$ ocasião das entrevistas foi aplicado um questionário semi-estruturado de modo a coletar as seguintes informaçóes: 1. dados atributivos que incluíram a instituição do entrevistado no intuito de classificar os atores nas categorias sociedade civil, setor público e setor privado, e a pergunta "Quais sáo os aspectos mais importantes para promover o desenvolvimento da regiāo?" com objetivo de analisar a diversidade de perspectivas dos atores, e 2. dados relacionais sobre o diálogo entre os atores por meio da pergunta: Com quem você costuma dialogar sobre os temas seguintes: desenvolvimento regional, questóes fundiárias, questóes florestais, conservação, normas ambientais, e Plano BR163 Sustentável? As perguntas associadas à coleta dos dados relacionais foram utilizadas para a identificação dos novos atores a serem entrevistados, viabilizando a construção de uma rede de atores envolvidos nos diversos temas mencionados acima que, daqui para frente, serão coletivamente identificados como temas ou questóes socioambientais. Nos dezesseis municípios, foram identificados e entrevistados 505 atores sociais que apresentam atuação direta nas questóes socioambientais. Foi considerado que existe uma relação de diálogo entre duas pessoas quando no mínimo uma delas cita a outra. Os dados sobre as relaçóes de diálogo entre os 505 atores entrevistados foram armazenados em uma planilha ator versus ator, usando o programa UCInet (Borgatti et al. 2002) e exportadas para o programa Netdraw (Borgatti 2002) para visualização das estruturas de rede. Além disso, para mapear a rede de diálogo entre os municípios do Portal da Amazônia, as relaçóes de diálogo foram agrupadas por meio da função "collapse" do programa UCInet, de modo a calcular o número médio de relaçôes de diálogo entre os atores de um mesmo município e entre os atores de municípios diferentes.

\section{Medida de rede utilizada como indicador de capital social}

Baseado na ideia que diversas configuraçốes de redes permitem o acesso e a mobilização de recursos distintos, Borgatti et al. (1998) propuseram uma série de indicadores de capital social a partir de medidas estruturais das redes sociais. A medida que utilizamos aqui é baseada no conceito de densidade. A densidade de uma rede é o número de elos existentes divididos pelo número de elos potenciais, que existiriam se todos os nós da rede estivessem conectados com os demais (Wasserman e Faust 1994). A comparação da densidade de redes sociais de tamanhos diferentes, como é o caso dos diversos municípios do Portal da Amazônia, é problemática porque a densidade tende a diminuir quando o número de nós da rede aumenta (Scott 2000). O número médio de elos por nó foi utilizado como medida alternativa para avaliar a densidade da rede (Bodin e Crona 2008). Considera-se que quanto maior o número de elos por nó, maior o capital social (Borgatti et al. 1998). O número médio de relação de diálogo por indivíduo com indivíduos do mesmo município e de outros municípios foi utilizado, respectivamente, como indicador de capital social de ligação e de conexão.

\section{RESULTADOS}

\section{Caracterização dos entrevistados e da rede de diálogo}

Em média, foram entrevistados 32 atores por município, com um mínimo de 15 indivíduos em Nova Santa Helena e um máximo de 63 em Alta Floresta. A Tabela 1 apresenta o número de habitantes de cada município (Instituto Brasileiro de Geografia e Estatística 2007) e a distribuição dos atores entrevistados por municípios.

A diversidade de interesses e prioridades entre os atores do Portal da Amazônia são revelados nas respostas dos entrevistados em relação aos aspectos que consideram mais importantes para promover o desenvolvimento da região. Os aspectos mencionados podem ser organizados seguindo as três principais dimensóes do desenvolvimento sustentável: econômica, social e ambiental. A dimensão econômica inclui os aspectos de infraestrutura, escoamento da produção, asfaltamento das estradas e incentivos ao agronegócio, à indústria e à agricultura familiar. Os temas de educação, saúde, organização social, conscientização das populações, associativismo foram frequentemente citados na dimensão social do desenvolvimento sustentável. Os aspectos de preservação dos ecossistemas terrestres e dos recursos hídricos são mencionados no que diz respeito à dimensão ambiental. Porém, diversos aspectos considerados prioritários para o desenvolvimento do Portal da Amazônia incorporam duas ou mesmo as três dimensôes do desenvolvimento sustentável. Por exemplo, os atores defendem a importância de desenvolver sistemas agroflorestais, ecoturismo, agroecologia, produção orgânica, agricultura familiar, economia solidária e de promover regularização fundiária, reforma agrária, produção local e cooperativas.

Os dados permitiram agrupar 495 dos 505 atores entrevistados em três amplas categorias: sociedade civil $(n=156)$, setor público $(n=258)$ e setor privado $(n=81)$. A categoria sociedade civil inclui atores que pertencem a cooperativas, associaçóes comunitárias, associações profissionais, movimentos sociais, sindicatos, entidades beneficentes, entidades religiosas, fundaçóes e organizaçóes não-governamentais. A categoria setor público abrange membros de instituiçóes e órgáos vinculados a governos 
Tabela 1 - Caracterização da população de estudo e indicadores de capital social dos atores sociais dos 16 municípios do Portal da Amazônia

\begin{tabular}{|c|c|c|c|c|c|c|c|c|c|}
\hline \multirow[t]{2}{*}{ Municípios } & \multirow{2}{*}{$\begin{array}{l}\text { População } \\
\text { (2007) }\end{array}$} & \multirow[t]{2}{*}{$\mathrm{n}^{1}$} & \multicolumn{2}{|c|}{$\mathrm{DT}^{2}$} & \multicolumn{2}{|c|}{$\begin{array}{c}\mathrm{Dl}^{3} \\
\text { Capital social de ligação } \\
\end{array}$} & \multicolumn{2}{|c|}{$\begin{array}{c}\mathrm{DE}^{4} \\
\text { Capital social de conexão }\end{array}$} & \multirow[t]{2}{*}{$\% \mathrm{DE} / \mathrm{DT}^{5}$} \\
\hline & & & Soma & Média & Soma & Média & Soma & Média & \\
\hline $\mathrm{AF}$ & 49.140 & 63 & 717 & 11,4 & 456 & 7,2 & 261 & 4,1 & 36 \\
\hline AP & 7.926 & 33 & 203 & 6,2 & 162 & 4,9 & 41 & 1,2 & 20 \\
\hline $\mathrm{CA}$ & 12.108 & 30 & 209 & 7,0 & 154 & 5,1 & 55 & 1,8 & 26 \\
\hline $\mathrm{CO}$ & 30.695 & 29 & 157 & 5,4 & 94 & 3,2 & 63 & 2,2 & 40 \\
\hline GA & 30.754 & 37 & 219 & 5,9 & 146 & 3,9 & 73 & 2,0 & 33 \\
\hline MR & 14.084 & 29 & 213 & 7,3 & 188 & 6,5 & 25 & 0,9 & 12 \\
\hline MT & 14.243 & 33 & 148 & 4,5 & 100 & 3,0 & 48 & 1,5 & 32 \\
\hline NB & 12.742 & 33 & 184 & 5,6 & 146 & 4,4 & 38 & 1,2 & 21 \\
\hline NC & 12.652 & 25 & 100 & 4,0 & 68 & 2,7 & 32 & 1,3 & 32 \\
\hline$N G$ & 4.877 & 19 & 128 & 6,7 & 94 & 4,9 & 34 & 1,8 & 27 \\
\hline NV & 8.133 & 46 & 250 & 5,4 & 212 & 4,6 & 38 & 0,8 & 15 \\
\hline NS & 3.347 & 15 & 83 & 5,5 & 46 & 3,1 & 37 & 2,5 & 45 \\
\hline NM & 6.725 & 29 & 155 & 5,3 & 110 & 3,8 & 45 & 1,6 & 29 \\
\hline PR & 11.540 & 28 & 160 & 5,7 & 114 & 4,1 & 46 & 1,6 & 29 \\
\hline PA & 28.987 & 21 & 76 & 3,6 & 54 & 2,6 & 22 & 1,0 & 29 \\
\hline TN & 14.584 & 35 & 382 & 10,9 & 218 & 6,2 & 164 & 4,7 & 43 \\
\hline Portal & 262.537 & 505 & 3384 & 6,7 & 2362 & 4,7 & 1022 & 2,0 & 30 \\
\hline
\end{tabular}

Ver material e métodos para a legenda dos nomes dos municípios. 1. n: número de atores entrevistados. 2. DT: Diálogo total: Soma das relações de diálogo dos atores do município (soma) e número médio de relações de diálogo dos atores do município (média). 3. Dl: Diálogo interno: Soma das relações de diảlogo entre os atores de um mesmo município (soma) e número médio de relações de diálogo entre os atores de um mesmo município (média). 4. DE: Diálogo externo: Soma das relações de diálogo dos atores do município com os atores dos outros municípios (soma) e número médio de relações de diálogo dos atores do município com atores dos outros municípios (média). 5. \% DE / DT: Percentagem das relações de diálogo com outros municípios em relação ao número total de relações de diálogo.

municipais, estaduais e federal. Os indivíduos categorizados como setor privado atuam em beneficio de interesses privados ou particulares, incluindo representantes da iniciativa privada, empresas particulares, representantes do comércio, empresários, madeireiros e fazendeiros, entre outros.

Estas três categorias são heterogêneas e incluem representantes com pontos de vista e projetos de desenvolvimento distintos. Por exemplo, os membros da sociedade civil incluem representantes de ONGs com foco no meio ambiente, de cooperativas voltadas para a agricultura familiar e de associaçôes de madeireiros. O setor público também inclui representantes vinculados a projetos políticos diversos e interesses potencialmente conflituosos. A Tabela 2 apresenta a percentagem dos atores que mencionam aspectos econômicos, sociais e ambientais nas suas respostas à pergunta sobre os aspectos que consideram mais importantes para promover o desenvolvimento da região. O setor público, a sociedade civil e o setor privado priorizam os aspectos econômicos em relação aos aspectos sociais e ambientais do desenvolvimento. $\mathrm{O}$ setor privado se distingue significativamente dos dois outros grupos e acorda uma importância menor à dimensão social do desenvolvimento. A heterogeneidade dos interesses dos atores é revelada mais claramente quando se analisa os aspectos prioritários para o desenvolvimento da região por categorias setoriais de atividades produtivas e/ou profissionais (Tabela 2). Os atores dos setores agrícola e pecuário levam em
Tabela 2 - Percentagem das categorias de atores que consideram os aspectos econômicos, sociais e ambientais importantes para 0 desenvolvimento do Portal da Amazônia

\begin{tabular}{lccccc}
\hline & \multicolumn{5}{c}{$\begin{array}{c}\text { Aspectos importantes para o desenvolvimento do } \\
\text { Portal da Amazônia }\end{array}$} \\
\hline $\begin{array}{l}\text { Categorias de } \\
\text { ator }\end{array}$ & $n$ & Econômicos & Sociais & Ambientais & $\begin{array}{c}\text { Econômicos, } \\
\text { sociais e } \\
\text { ambientais }\end{array}$ \\
\hline Setor público & 258 & 89 & 60 & 27 & 19 \\
Sociedade civil & 156 & 90 & 62 & 26 & 17 \\
Setor privado & 81 & 90 & 43 & 28 & 15 \\
\hline Total & 495 & 89 & $58^{*}$ & 27 & 18 \\
\hline Setor agrícola & 105 & 90 & 60 & 15 & 13 \\
Setor pecuário & 18 & 94 & 44 & 6 & 0 \\
$\begin{array}{l}\text { Setor } \\
\text { madeireiro }\end{array}$ & 23 & 96 & 35 & 48 & 22 \\
Setor ambiental & 37 & 86 & 57 & 51 & 30 \\
\hline Total & 183 & 90 & 55 & $26^{\star \star *}$ & $18^{\star}$ \\
\hline
\end{tabular}

${ }^{*} p<0,05,{ }^{* *} p<0,001$, Chi Quadrado

consideraçáo a dimensão ambiental do desenvolvimento em uma proporção significativamente menor do que os atores dos setores madeireiro e ambiental. Nenhum ator do setor pecuário menciona todas as três dimensôes da sustentabilidade na definiçấo das prioridades para o desenvolvimento da regiấo. A heterogeneidade de interesses revelados no Portal da Amazônia aponta para desafios nos processos de governança 
e para a relevância do diálogo entre os atores, tanto em nível territorial quanto municipal, para integrar a diversidade de perspectivas e minimizar os possíveis conflitos em torno de um projeto de desenvolvimento territorial.

Foram mapeadas 3384 relaçôes de diálogo entre os 505 atores do Portal, com uma média de 6,7 parceiros de diálogo por ator (Tabela 1). Para revelar o padrão de diálogo em nível municipal, as relaçóes mapeadas entre os indivíduos foram agregadas por município, de modo a revelar a soma das relaçóes entre os atores do mesmo município e, também, entre atores de municípios diferentes. A média de relaçôes de diálogo por município varia de 3,6 em Peixoto de Azevedo até 11,4 em Alta Floresta (Tabela 1 - DT: Diálogo total).

\section{O capital social em nível municipal}

No intuito de mapear os dois tipos de capital social, diferenciamos na Tabela 1 as relaçóes de diálogos que os atores possuem dentro do município (DI, diálogo interno: capital social de ligação) e as relaçóes que eles possuem com atores de outros municípios (DE, diálogo externo: capital social de conexão). As médias do número de relações de diálogo entre os atores do mesmo município variam consideravelmente: de somente 2,6 para Peixoto de Azevedo até valores acima de 6,0 para Marcelândia, Terra Nova e Alta Floresta. As médias do número de relaçóes dos atores de cada município com atores de outros municípios também mostram variação considerável: de valores iguais ou menores de 1,0 para os municípios de Peixoto de Azevedo, Marcelândia e Nova Monte Verde, a valores acima de 4,0 para Terra Nova e Alta Floresta. A percentagem das relaçôes de diálogo com atores de outros municípios é menor do que $50 \%$ para todos os municípios. A comparação entre os padrôes de relaçóes de diálogo dos grupos sociais dos diferentes municípios permite estabelecer uma classificação em função dos respectivos níveis de capital social, de ligação e de conexão, e discutir os possíveis papéis dos atores de cada município nos processos de governança ambiental no Território (Tabela 3).

\section{O capital social em nível territorial}

A figura 2 ilustra a rede de diálogo entre os atores do Portal da Amazônia agrupados por município. A rede de diálogo entre municípios não está fragmentada. Os 16 municípios fazem parte de um grande componente, ou seja, estão conectados diretamente ou por meio de outro(s) município(s). As relaçóes internas e entre atores de municípios diferentes correspondem, respectivamente, a 70 e $30 \%$ do total. Esta configuração, na qual os atores possuem internamente ao município uma densa rede de diálogo e estáo conectados entre si por uma rede de relaçóes intermunicipais, mais esparsa, indica um equilíbrio entre o capital social de ligação e de conexão em nível territorial. Alta Floresta e Terra Nova são os dois únicos municípios que dialogam com todos os outros 15 municípios do Portal e aparecem como os dois municípios chave para a
Tabela 3 - Classificação dos atores sociais dos diferentes municípios de acordo com os níveis de capital social de ligação e de conexão

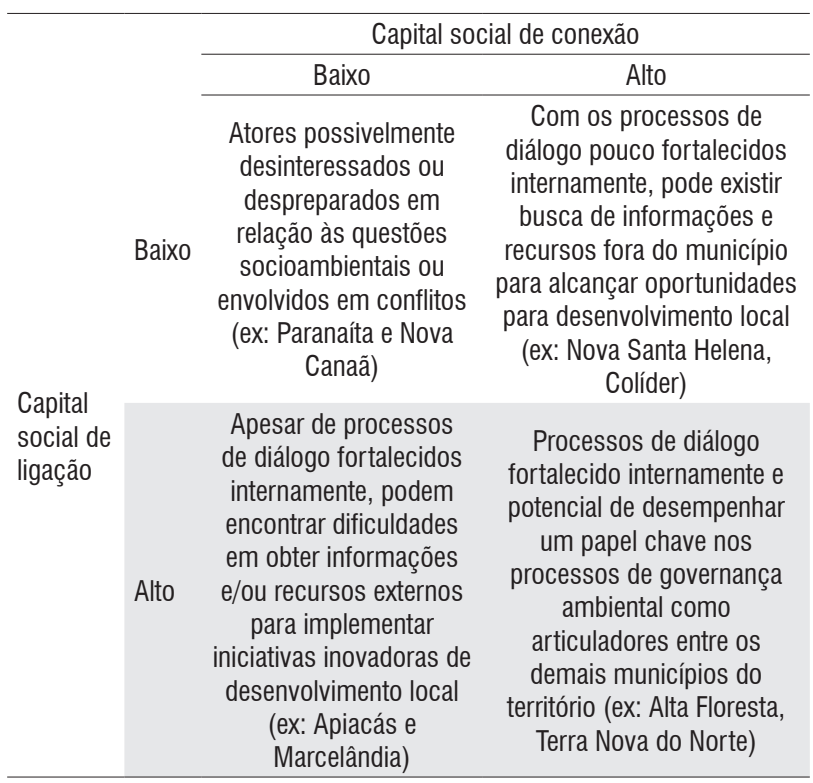

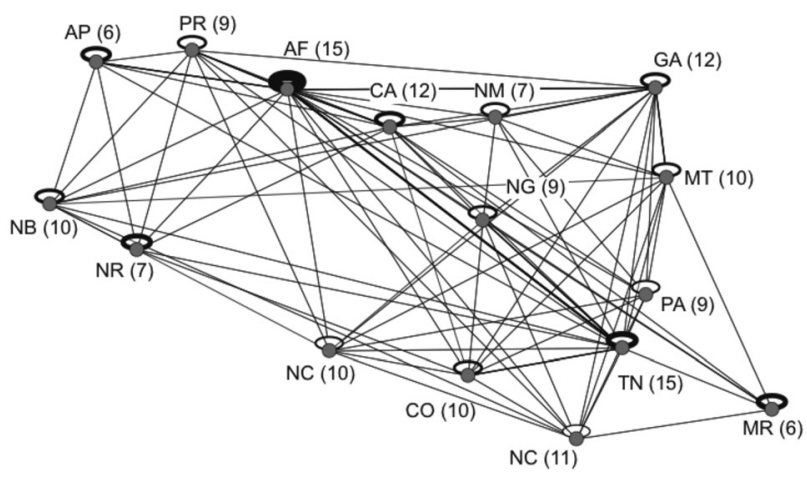

Figura 2 - Rede de diálogo sobre temas socioambientais entre os 505 atores do Portal da Amazônia agrupados por municípios. Os atores agrupados por municípios foram espacializados com intuito de facilitar a visualização das relações e de modo a refletir aproximadamente a posição geográfica. 0 tamanho de cada elo é proporcional ao número médio de relações de diálogo entre os atores do mesmo município (linhas reflexivas) e entre pares de municípios (linhas retas). Os números entre parênteses indicam o número de municípios com os quais os grupos de atores de cada município possuem relação de diálogo.

conectividade do Território. Apiacás e Marcelândia, os dois municípios localizados nos extremos geográficos do Território, possuem conexôes com somente seis outros municípios.

\section{A rede de diálogo em ação - As Agendas 21 Locais no Portal da Amazônia.}

Embora não seja objetivo desse artigo analisar qualitativamente como ocorrem as relaçóes de diálogo entre os atores do Portal, apresentamos a seguir um exemplo de 
política que é desenvolvida a partir da rede de diálogo. Tal exemplo se refere à proliferação de projetos de Agendas 21 locais em oito dos 16 municípios do Portal (Alta Floresta, Carlinda, Guarantã do Norte, Marcelândia, Matupá, Novo Mundo, Peixoto de Azevedo, Terra Nova do Norte). Para o Ministério do Meio Ambiente, a Agenda 21 local é (Ministério do Meio Ambiente 2003: 31):

Um processo participativo multissetorial de construçáo de um programa de ação estratégico dirigido às questôes prioritárias para o desenvolvimento sustentável local. Como tal, deve aglutinar os vários grupos sociais na promoção de uma série de atividades no nível local, que impliquem mudanças no atual padrão de desenvolvimento, integrando as dimensôes sócio-econômicas, político-institucionais, culturais e ambientais da sustentabilidade.

Em pesquisa realizada pelo Ministério do Meio Ambiente (2009), foi constatado que esses projetos geralmente envolvem articulações entre governo (nos diversos níveis), empresas e sociedade civil dentro de cada município e, por vezes, há a participação de atores de outros municípios do Portal e mesmo de outros municípios que não pertencem ao Território. Além de realizar atividades de diagnóstico participativo e de construçáo de um Plano Local de Desenvolvimento Sustentável, alguns dos projetos de Agenda 21 criaram el ou potencializaram programas para a gestão ambiental em nível local e regional (Fonseca 2009), tais como o projeto Y Ikatu Xingu, programa de recuperaçáo de nascentes e matas ciliares que tem atuação em diversos municípios do Portal (http://www.yikatuxingu.org.br/). Este programa envolve componentes de reflorestamento e educação ambiental e conta, entre seus proponentes e parceiros, com grupos e organizaçóes indígenas, ONGs ambientalistas, governos municipais, empresas privadas, escolas municipais, entre outros. Os projetos oriundos ou potencializados pela Agenda 21 se caracterizam pelo diálogo entre atores internos aos municípios ou pelo diálogo destes com atores e organizações de outros municípios da região.

Embora os oito projetos de Agenda 21 tenham apresentado resultados distintos entre si, em variadas formas e graus de sucesso - desde projetos com diversas ações concretas e continuidade ao longo do tempo a projetos sem açóes práticas e sem continuidade - os projetos tenderam a ser mais efetivos nos municípios de Marcelândia, Alta Floresta e Terra Nova do Norte (Ministério do Meio Ambiente 2009). Estes três municípios representam aqueles de maior índice relacionado ao capital social de ligação e Terra Nova do Norte e Alta Floresta também lideram o índice relacionado ao capital social de conexão (Tabela 1). Desta forma, em tais projetos é percebido como as redes de diálogo podem ter influenciado no estabelecimento e no fomento de políticas e projetos de cunho socioambiental no Território.

\section{DISCUSSÃO}

A análise da rede de diálogo entre um conjunto de atores envolvidos com questóes socioambientais no Portal da Amazônia possibilitou compreender melhor o papel do Território enquanto espaço social de articulaçáo e de negociação, sobre um conjunto de temas que é chave para o desenvolvimento, e a gestáo dos recursos naturais. $\mathrm{O}$ padrăo de conectividade revela um potencial de comunicação na escala do Portal da Amazônia, bem como indica uma participação diferenciada dos atores dos diversos municípios na governança ambiental do Território. A existência de oportunidades de diálogo entre os municípios do Portal da Amazônia indica um potencial de fomentar açóes coordenadas e pactuadas entre os diversos atores sociais, ainda que o diálogo, para ser efetivo, necessite da complementaçáo de avanços em termos socioeconômicos, de educação e de acesso à informação.

Os municípios de Alta Floresta e de Terra Nova se destacam como os pólos de diálogo no Portal da Amazônia com altos níveis de capital social de ligação e de conexão. Ambos ocupam uma posição geográfica central no Território, no entanto, se diferenciam quanto às características das instituiçôes com papéis relevantes na temática socioambiental. Alta Floresta é a sede de diversas ONGs ambientalistas com conexóes nacionais e internacionais, enquanto que Terra Nova é destaque na regiáo pela relevância sociopolítica de duas cooperativas voltadas para produção agrícola.

Os resultados apresentados fazem emergir questionamentos a serem desenvolvidos em pesquisas futuras. $\mathrm{O}$ primeiro deles é o repensar do conceito de território tal como é delimitado pelo programa Territórios da Cidadania. O caso do município de Marcelândia permite levantar este questionamento. Um dos mais efetivos projetos de Agenda 21 ocorreu neste município. Pela análise da rede de diálogo, percebe-se que o município de Marcelândia teria alto capital social de ligação, mas baixo capital de conexáo, enquanto que os outros casos bem sucedidos de Agenda 21 (Alta Floresta e Terra Nova do Norte) apresentam altos índices de capital social tanto de ligação quanto de conexão. Seria esperado que o município de Marcelândia possuísse um capital social de conexão alto, pelos resultados que a Agenda 21 obteve em tal município (Ministério do Meio Ambiente 2009). Entretanto, o município de Marcelândia está situado na microrregiáo 524 - Sinop/Norte Matogrossense. O município de Sinop é um polo regional no Norte do Estado do Mato Grosso, possui população de cerca de 115.000 pessoas e tem economia fortalecida ligada ao setor agropecuário e à indústria madeireira. O município de Marcelândia está situado a uma distância geográfica semelhante dos dois municípios e seria natural que os habitantes de Marcelândia mantivessem relaçóes com habitantes de Sinop. Esta proximidade entre os grupos sociais de Sinop e de Marcelândia foi notada em estudo de campo realizado por Fonseca (2009). Estas 
observaçóes levantam a possibilidade de que o capital social de conexão de Marcelândia não tenha sido revelado pelo presente estudo, porque estaria associado às relaçôes mantidas com atores de municípios que não fazem parte do Portal da Amazônia. Dessa forma, este estudo revela que, por vezes, a delimitação de um território feita de cima para baixo por um órgão governamental pode eclipsar relaçôes de diálogo entre atores e municípios que não são captadas pela delimitação do Território. Na medida em que a fronteira de um Território da Cidadania serve como fator restritivo para incentivos aos municípios e para atuação de políticas públicas, é possível questionar a delimitaçáo do Território, na medida em que tal delimitação não corresponde às relaçóes sociais efetivas entre os atores de todos os municípios do Portal da Amazônia. No caso demonstrado, uma redefinição do Território Portal da Amazônia pode se fazer necessária, abrindo possibilidades para repensar o conceito de Território da Cidadania.

Um segundo ponto se refere às possíveis relações entre o fortalecimento da rede de diálogo e a efetividade de políticas públicas no Território. $\mathrm{O}$ exemplo demonstrado sugere que as Agendas 21 foram potencializadas pela existência da rede de diálogo, mas ainda é necessário analisar em que medida a efetividade de projetos socioambientais é oriunda da rede de diálogo e em que medida ela é devida a outros fatores presentes no contexto local. A ampliação da análise, de cunho qualitativo, incluindo outros projetos e políticas incidentes na regiâo, tem o potencial de identificar, de forma mais acurada, o papel que a rede de diálogo desempenha no sucesso de políticas locais e regionais.

O terceiro ponto está relacionado ao fomento e reprodução da rede de diálogo. Embora a rede de diálogo possa potencializar o efeito de políticas e projetos socioambientais, a própria atuação destes projetos, na medida em que estes envolvem a interação entre diversos atores locais, pode servir como meio de ampliaçáo da rede de diálogo e de fomento de capital social. Caso isso ocorra, é possível que haja o estabelecimento de um círculo virtuoso envolvendo projetos e redes de diálogo. A análise de como este mecanismo funciona tem o potencial de gerar açóes concretas que visem o fomento de características contextuais que contribuam para o estabelecimento desse círculo.

O quarto ponto se refere à importância em examinar as relaçóes que os atores do Portal da Amazônia possuem com os atores externos ao Território, como gestores e representantes políticos estaduais ou federais e ONGs nacionais ou internacionais. Estas relaçóes merecem ser estudadas para analisar a capacidade dos municípios em mobilizar recursos externos para o Território e em influenciar decisóes políticas no âmbito estadual, federal ou mesmo global, com possível impactos locais ou regionais.

\section{Prioridades para ações de desenvolvimento no Portal da Amazônia}

A análise do padrão de diálogo no Portal da Amazônia oferece a possibilidade de sugerir algumas iniciativas para fortalecer a unidade, o diálogo e a cooperação no Território, e assim promover o desenvolvimento e o uso sustentável dos recursos naturais. Nos municípios com atores com baixo capital social de ligação é importante estimular os processos de diálogo internos entre esses atores. Diversas estratégias, tais como o fortalecimento dos movimentos sociais voltados para as questôes ambientais podem ser implementadas a partir de um diagnóstico das causas da ausência de diálogo em cada município. No caso dos municípios com um nível baixo de capital social de conexão no Território, é prioritário reforçar os processos de integraçáo, por meio de incentivos à participação nos espaços de diálogos formais e informais que existem no Território. Iniciativas de gestão dos possíveis conflitos, que podem ter suas raízes tanto na diversidade de interesses dos atores quanto nas diferentes posiçóes de poder envolvidas, são também relevantes para promoção do diálogo em nível municipal e regional. A promoção de tais açôes pode desencadear melhorias na formulação e na implementação de políticas públicas direcionadas para a região.

Os resultados da pesquisa serão compartilhados com os atores que participaram das entrevistas e em diversos espaços de diálogo do Território. Espera-se que essas informaçóes sejam úteis para que os atores possam incrementar sua compreensão dos processos de comunicação, em nível local e para além das fronteiras dos seus respectivos municípios, a fim de fortalecer os processos de diálogo, diminuir os conflitos e promover o uso sustentável dos recursos naturais. Espera-se também que o presente estudo contribua para guiar novas pesquisas em que o mapeamento das redes sociais seja utilizado para estudar o capital social no intuito de analisar empiricamente as relaçôes entre os aspectos estruturais da organização social e os processos de desenvolvimento sustentável e de governança ambiental.

\section{AGRADECIMENTOS}

Este trabalho recebeu o apoio do Programa sobre florestas tropicais e outras florestas em países em desenvolvimento da Comissão Européia. Os autores agradecem o apoio e a colaboração do Instituto Centro de Vida (ICV) nas atividades de campo realizadas nos municípios do Portal da Amazônia.

\section{BIBLIOGRAFIA CITADA}

Abramovay, R. 2000. The social capital of territories: re-thinking rural development. Economia Aplicada, 4: 379-397 (in Portuguese).

Armitage, D. 2008. Governance and the commons in a multi-level world. International Journal of the Commons, 2: 7-32. 
Bebbington, A. 2004. Social capital and development studies 1: critique, debate, progress? Progress in Development Studies, 4: 343-349.

Bebbington, A.; Perreault, T. 1999. Social capital, development, and access to resources in highland Equador. Economic Geography, 75: 395-418.

Bodin, O.; Crona, B.I.; Ernstson, H. 2006. Social Networks in Natural Resource Management: What Is There to Learn from a Structural Perspective? Ecology and Society, 11: r2.

Bodin, O.; Crona, B.I. 2008. Management of natural resources at the community level: exploring the role of social capital and leadership in a rural fishing community. World Development, 36: $2763-2779$.

Bodin, O.; Crona, B.I. 2009. The role of social networks in natural resource governance: What relational patterns make a difference? Global Environmental Change, 19: 366-374.

Borgatti, S.P. 2002. NetDraw: Graph Visualization Software. Analytic Technologies, Harvard, MA, USA.

Borgatti, S.P.; Everett, M.G.; Freeman, L.C. 2002. Ucinet for Windows: Software for Social Network Analysis, Analytic Technologies, Harvard, MA, USA.

Borgatti, S.P.; Jones, C.; Everett, M.G. 1998. Network Measures of Social Capital. Connections, 21: 28-36.

Bouma, J.; Bulte, E.; van Soest, D. 2008. Trust and cooperation: Social capital and community resource management. Journal of Environmental Economics and Management, 56: 155-166.

Bourdieu, P. 1980. Social capital. Actes de la recherche en sciences sociales, 31: 2-3 (in French).

Brondizio, E.S.; Ostrom, E.; Young, O.R. 2009. Connectivity and the Governance of Multilevel Social-Ecological Systems: The Role of Social Capital. Annual Review of Environment and Resources, 34: 253-278.

Carlsson, L.; Sandström, A. 2008. Network governance of the commons. International Journal of the Commons, 2: 33-54.

Cash, D.W.; Adger, W.; Berkes, F.; Garden, P.; Lebel, L.; Olsson, P.; Pritchard, L.; Young, O. 2006. Scale and cross-scale dynamics: governance and information in a multilevel world. Ecology and Society, 11: 8 .

Coleman, J. 1988. Social capital in the creation of human capital. American Journal of Sociology, 94: 95-120.

Crona, B.; Bodin, O. 2006. WHAT you know is WHO you know? Communication patterns among resource extractors as a prerequisite for co-management. Ecology \& Society, 11: 7.

de Oliveira, M.S. 2009. Culture and politics of social and environmental movements in the region of the BR-163 highway, Cuiabá-Santarém, p. 77-94. In: Oliveira D. (Eds). Territorial development: guidelines for the BR-163 region. WWF-Brasil, Brasília, DF (in Portuguese).

Dietz, T.; Ostrom, E.; Stern, P.C. 2003. The Struggle to Govern the Commons. Science, 302: 1907-1912.

Folke, C.; Hahn, T.; Olsson, P.; Norberg, J. 2005. Adaptive governance of social-ecological systems. Annual Review of Environment and Resources, 30: 441-473.
Fonseca, I.F. 2009. Between discourse and practice: good governance and Agenda 21 in the Amazon. Dissertação de Mestrado, Centro de Desenvolvimento Sustentável/Universidade de Brasília, Brasília, DF. 166 pp. (in Portuguese).

Forget, G.; Lebel, J. 2001. An ecosystem approach to human health. International Journal of Occupational and Environmental Health, 7 Suppl:1-36.

Olival A. de A. 2005. Propositive study: the Amazonian Gateway Territory. Ministério do Desenvolvimento Agrário/Fundação Cândido Rondon, Brasília, DF. 159 pp (in Portuguese).

Grafton, R.Q. 2005. Social capital and fisheries governance. Ocean \& Coastal Management, 48: 753-766.

Granovetter, M.S. 1973. The strength of weak ties. American Journal of Sociology, 78: 1360-1380.

Grindle, M. 2004. Good enough governance: poverty reduction and reform in developing countries. Governance: An International Journal of Policy, Administration, and Institutions, 17: 525-548.

Holling, C.S.; Meffe, G.K. 1996. Command and Control and the Pathology of Natural Resource Management. Conservation Biology, 10: 328-337.

Instituto Brasileiro de Geografia e Estatística. 2007. Counting of the population - census 2007. IBGE, Rio de Janeiro, RJ, Brazil (in Portuguese).

Lemos, M.; Agrawal, A. 2006. Environmental governance. Annual Review of Environment and Resources, 31: 297-325.

Lin, N. 1999. Building a Network Theory of Social Capital. Connections, 22: 28-51.

Marin, A.; Wellman, B. 2010. Forthcoming in: Carrington, P.; Scott, J. (Eds). Handbook of Social Network Analysis. Sage, Thousand Oaks, CA, USA.

Mertens, F; Saint-Charles, J.; Lucotte, M.; Mergler, D. 2008. Emergence and robustness of a community discussion network on mercury contamination and health in the Brazilian Amazon. Health Education and Behavior, 35: 509-521.

Mertens, F.; Saint-Charles, J.; Mergler, D.; Passos, C.J.; Lucotte, M. 2005. A network approach for analysing and promoting equity in participatory Ecohealth research. Ecohealth, 2: 116-123.

Ministério do Desenvolvimento Agrário. 2006. Territorial plan of sustainable rural development Amazonian Gateway. Brasília, DF. $61 \mathrm{pp}$ (in Portuguese).

Ministério do Meio Ambiente, 2003. Building local Agenda 21. 2.ed. Ministério do Meio Ambiente, Brasília, DF. 62 pp (in Portuguese).

Ministério do Meio Ambiente, 2009. National research to identify the results of local Agenda 21 implementation processes in Brazil. Ministério do Meio Ambiente, Brasília, DF. Preliminary version (in Portuguese).

Newman, L.; Dale, A. 2007. Homophily and agency: creating effective sustainable development networks. Environment, Development and Sustainability, 9: 79- 90.

Portes, A. 1998. Social capital: its origins and applications in modern sociology. Annual Reviews of Sociology, 24: 1-24. 


\section{ACTA}

Pretty, J. 2003. Social capital and the collective management of resources. Science, 302: 1912-1914.

Pretty, J.; Ward, H. 2001. Social capital and the environment. World Development, 29: 209-227.

Putnam, R. 1995. Bowling alone: America's declining social capital. Journal of Democracy, 6: 65-78.

Sandström, A. 2008. Policy Networks: The relation between structure and performance. PhD Thesis, Luleå University of Technology, Luleå, Sweden. 212 pp.

Scherer-Warren, I. 2006. From mobilizations to networks of social movements. Sociedade \& Estado, 21: 109-130 (in Portuguese).

Schneider, M.; Scholz, J.; Lubell, M.; Mindruta, D.; Edwardsen, D. 2003. Building Consensual Institutions: Networks and the National Estuary Program. American Journal of Political Science, 47: 143-158.
Scott, J. 2000. Social network analysis: a handbook. Sage Publications Ltd, Thousand Oaks, CA, USA. 240 pp.

SDT/MDA - Secretária de Desenvolvimento Sustentável / Ministério do Desenvolvimento Agrário. 2005. Framework to support the development of rural territories. Série documentos institucionais, 2: 1-29 (in Portuguese).

Wasserman, S.; Faust, K. 1994. Social Network Analysis - Methods and Applications. Cambridge University Press, Cambridge, UK. $857 \mathrm{pp}$.

Woolcock, M.; Narayan, D. 2000. Social Capital: Implications for Development Theory, Research, and Policy. World Bank Research Observer, 15: 225-249.

Recebido em 28/07/2010

Aceito em 23/10/2010 
